\title{
Pitfalls in the Interpretation of Chicago Classification for Esophageal Motility Disorders
}

\author{
Fernando A M Herbella, ${ }^{1 *}$ Francisco Schlottmann, ${ }^{2}$ and Marco G Patti ${ }^{3}$ \\ ${ }^{I}$ Department of Surgery, Federal University of São Paulo, São Paulo, Brazil; ${ }^{2}$ Department of Surgery, Hospital Alemán of Buenos Aires, Buenos \\ Aires, Argentina; and ${ }^{3}$ Department of Medicine and Surgery, University of North Carolina at Chapel Hill, Chapel Hill, NC, USA
}

\begin{abstract}
High-resolution manometry permitted the creation of the Chicago classification, that is the categorization for esophageal motility disorders most currently used. Despite its wide acceptance, there are few pitfalls for the correct interpretation of the tests. This technique review illustrates some difficult cases that may lead to misinterpretation of the results. Difficult cases are analyzed, such as the distinction of: (1) esophagogastric junction morphology and lower esophageal sphincter excursion, (2) intrabolus pressure pattern or common cavity, (3) hypercontractile esophagus (jackhammer) and achalasia type III, (4) absent contractility and severe ineffective esophageal motility or achalasia type I, and (5) simultaneous distal esophageal spasm and ineffective esophageal motility.
\end{abstract}

(J Neurogastroenterol Motil 2021;27:513-517)

\section{Key Words}

Achalasia; Chicago classification; Esophageal manometry; Esophageal motility disorders; Lower esophageal sphincter

\section{Introduction}

The Chicago classification (CC) version 3.0 is the classification of esophageal motility disorders currently most in use. ${ }^{1}$ This classification standardized not only parameters based on high-resolution manometry ${ }^{2}$ but also re-classified motility disorders nomenclature and definition, ${ }^{3}$ and clearly impacted the management of patients with esophageal motility disorders. ${ }^{4}$ There are, however, few pitfalls for the correct interpretation of the tests. This technique review illustrates some difficult cases that may lead to misinterpretation of the results.

\section{Esophagogastric Junction Morphology or Lower Esophageal Sphincter Excursion}

CC divided esophagogastric junction morphology (EGJ) in 3 subtypes based on the overlap or disjunction of the 2 contractile elements of the EGJ: the lower esophageal sphincter (LES) and the crural diaphragm. ${ }^{5}$ Type II esophagogastric morphology is characterized by a separation (double-peaked pressure zone) of the LES and the diaphragm pressures more than $1 \mathrm{~cm}$ and less than $2 \mathrm{~cm}$. High-resolution manometry allowed a clear distinction of these 2 components, but it also allowed a clear view of the LES excursion during respiration ${ }^{6}$ that may be misinterpreted as a Type II EGJ morphology (Fig. 1).

Received: March 27, 2020 Revised: None Accepted: August 17, 2021

(.) This is an Open Access article distributed under the terms of the Creative Commons Attribution Non-Commercial License (http://creativecommons. org/licenses/by-nc/4.0) which permits unrestricted non-commercial use, distribution, and reproduction in any medium, provided the original work is properly cited.

${ }^{*}$ Correspondence: Fernando A M Herbella, MD

Department of Surgery, Escola Paulista de Medicina, Rua Diogo de Faria 1087 cj 301 Sao Paulo, SP 04037-003, Brazil

Tel: +55-11-999922824, Fax: +55-11999922824, E-mail: herbella.dcir@epm.br 

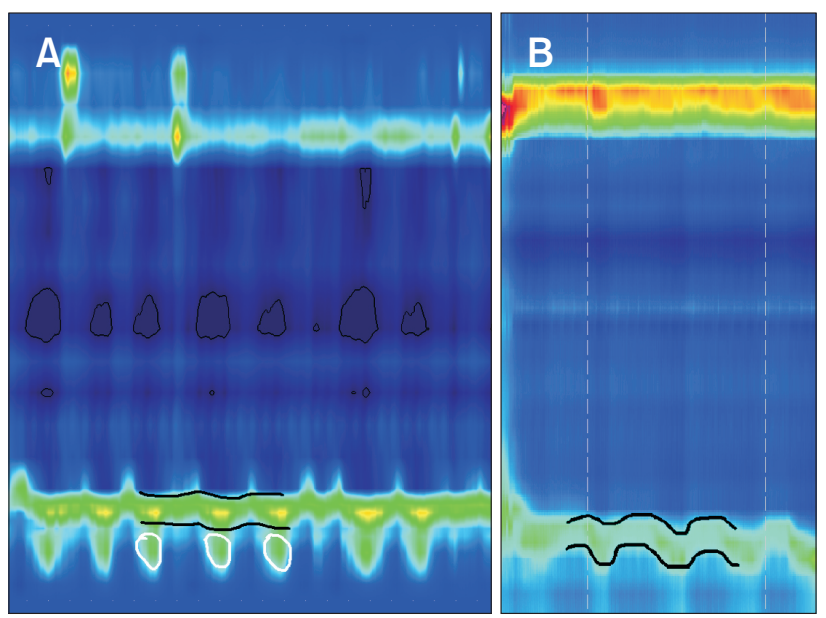

Figure 1. Type II esophagogastric morphology (A) is distinguished from lower esophageal sphincter (LES) respiratory upward and downward movement (B) based on a constant tonic contraction of the LES (black lines) seem above an interrupted phasic contraction of the diaphragm (white lines) while LES excursion is noticed as a moving isobaric tonic pressure (black lines).

\section{Intrabolus Pressure Pattern or Common Cavity}

CC defines the presence of intrabolus pressure as an abnormal pressurization of the esophagus above $30 \mathrm{mmHg} .{ }^{1}$ It may be panesophageal, compartmentalized or limited to the EGJ. Intrabolus pressure may be misunderstood as a common cavity (Fig. 2). Common cavity is a phenomenon characterized by the rise of intraesophageal pressure to the level of the gastric pressure. ${ }^{7}$ It occurs during LES opening, and it may be a marker for gastroesophageal reflux $^{7}$ or a transient relaxation of the LES. ${ }^{8}$ Artifacts due to air entrapment in the protective plastic shield may lead to a high pressure at the end of peristalsis, not before as in the previous situations.

\section{Hypercontractile Esophagus (Jackhammer) or Achalasia Type III}

Hypercontractile esophagus is defined by $\geq 20 \%$ of swallows with a distal contractile integral $>8000 \mathrm{mmHg} / \mathrm{sec} / \mathrm{cm}$. ${ }^{1}$ Type III achalasia is described as spastic contractions with distal contractile integral $>450 \mathrm{mmHg} / \mathrm{sec} / \mathrm{cm}$ with $\geq 20 \%$ of swallows. ${ }^{9}$ Both diseases present with hypertonic contractions making their distinction sometimes quite difficult (Fig. 3). LES relaxation may not discriminate between the 2 diseases. Achalasia is characterized by an elevated integrated relaxation pressure (IRP), ${ }^{10}$ but a "normal"

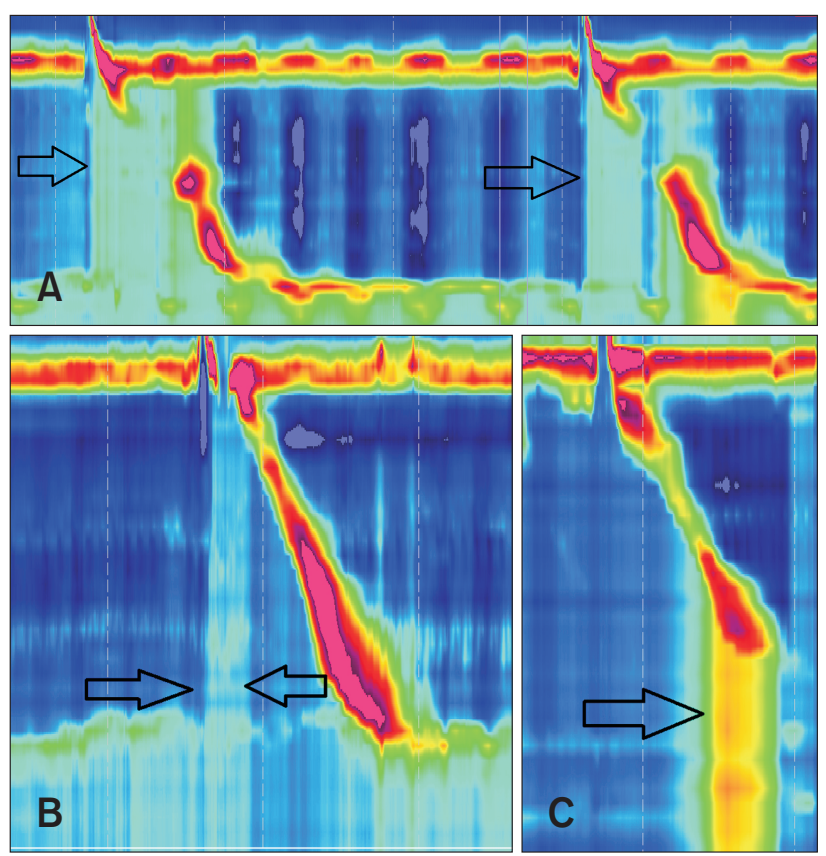

Figure 2. Intrabolus pressure (arrow; A) may be misunderstood as a common cavity (arrow; B). The first occurs only during swallows, occur until the peristalsis and always exceeds $30 \mathrm{mmHg}$ while a common cavity may occur in the absence of swallow during a transient relaxation of the lower esophageal sphincter, may slowly ascends creating a bell-shaped pressurization or do not persist until the peristalsis and it is isobaric to the gastric pressure (that rarely exceeds $30 \mathrm{mmHg}$ ). Artifact due to air entrapment in the protective shield is a high pressure at the end of peristalsis, not before as in the previous situations (arrow; C).

IRP may be noticed in some cases of achalasia since a LES basal pressure below $15 \mathrm{mmHg}$ is seem in a percentage of cases ${ }^{11}$ and relaxation pressure cannot be higher than basal pressure. In addition, the LES may be intentionally destroyed by treatment such as laparoscopic myotomy, pneumatic dilatation, and per oral endoscopic myotomy. On the other hand, jackhammer esophagus can coexist or be secondary to EGJ outflow obstruction, and thus present with an abnormal IRP. ${ }^{12}$ Distinction between diseases may be based solely on contraction patterns based on the distal latency since achalasia waves must be premature (Fig. 3).

\section{Absent Contractility or Severe Ineffective Esophageal Motility or Achalasia Type I}

Hypomotility diseases (absent contractility, severe ineffective esophageal motility, and achalasia type I) may present with almost inexistent waves (Fig. 4). While an altered IRP is characteristic of achalasia, not all cases may present with an elevated IRP as men- 

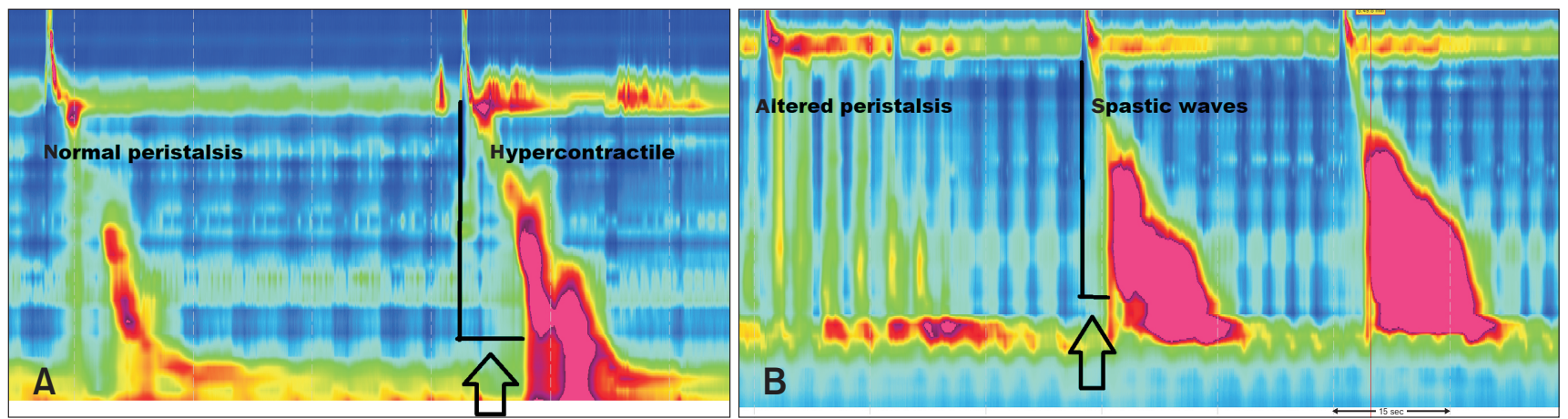

Figure 3. Distinction between hypercontractile esophagus (jackhammer; A) and achalasia type III (B) may be based on contraction pattern. Hypercontractile swallows must be premature in achalasia but with a normal distal latency (arrows) in jackhammer cases. Jackhammer waves are frequently multipeaked. Also, they may be discerned by the non-hypercontractile swallows that will show an altered peristalsis in achalasia (aperistalsis) but not in jackhammer cases.
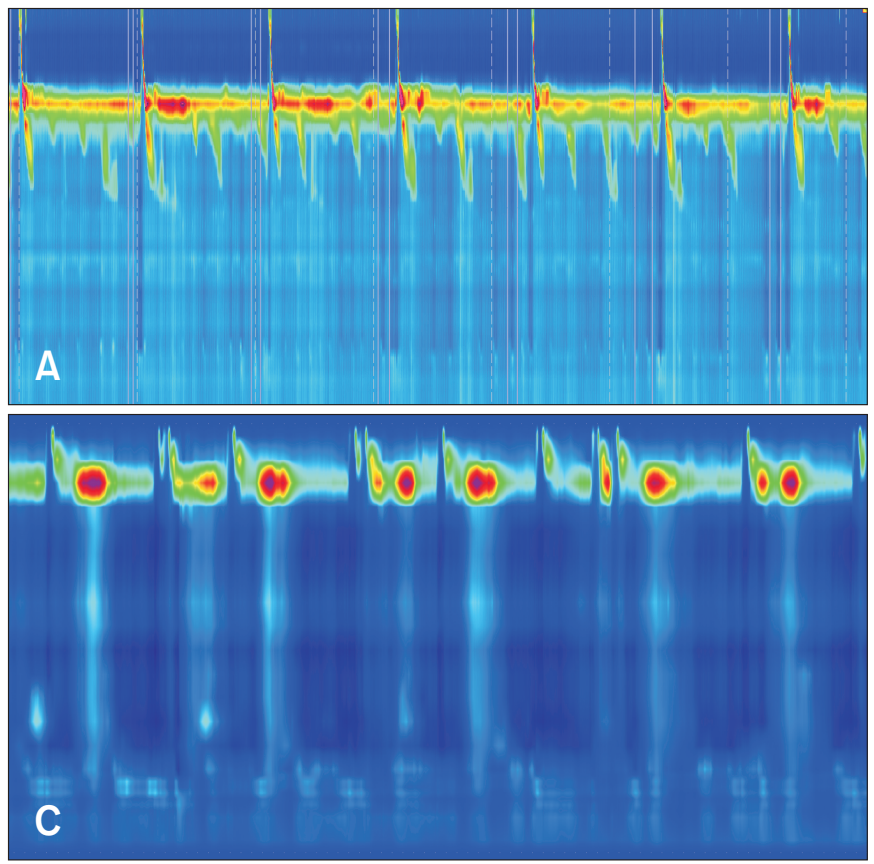

tioned before. Esophageal pressurization is characteristic of achalasia; however, pressurization may be minimal in some cases of type I. A residual subtle peristalsis may be noticed in ineffective esophageal motility and absent peristalsis if the causative disease (eg, connective tissue diseases) did not lead to complete absent peristalsis yet. Often, distinction among these diseases may be possible solely based on clinical grounds, such as the history of connective tissue diseases, long-term gastroesophageal reflux disease symptoms, origin from endemic areas of Chagas'disease, etc.

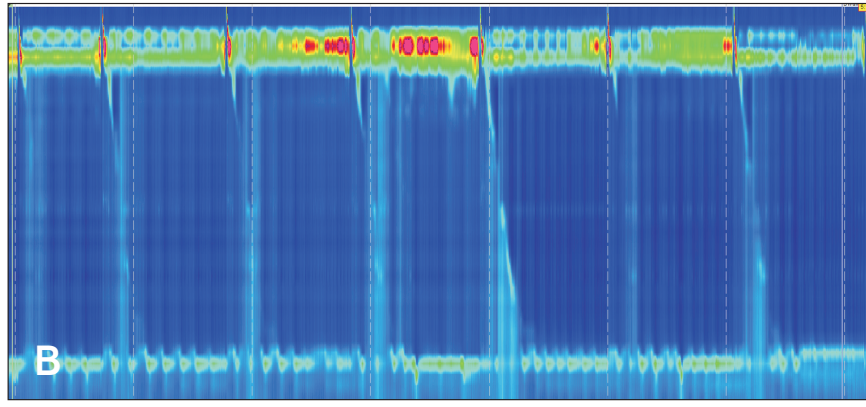

Figure 4. Absent contractility (scleroderma; A), severe ineffective esophageal motility (gastroesophageal reflux disease; B) and achalasia type I (post-myotomy; C) may have almost undetectable waves. Distinction among diseases may sometimes be possible solely based on clinical grounds.

\section{Distal Esophageal Spasm or Ineffective Esophageal Motility}

The manometric diagnosis of distal esophageal spasm and ineffective esophageal motility is easily achieved. There are, however, some patients that may overlap these diagnoses as having more than $20 \%$ of premature waves and more than $50 \%$ of ineffective swallows (Fig. 5). One must remember in these cases that there is a hierarchization of diagnosis (Fig. 6). Thus, major disorders of peristalsis precede the diagnosis of minor disorders. Although not 
expressed by the $\mathrm{CC}$, non-conflictive diagnosis may be simultaneously reported such as EGJ outflow obstruction in a patient with hypercontractile esophagus (but not with achalasia).

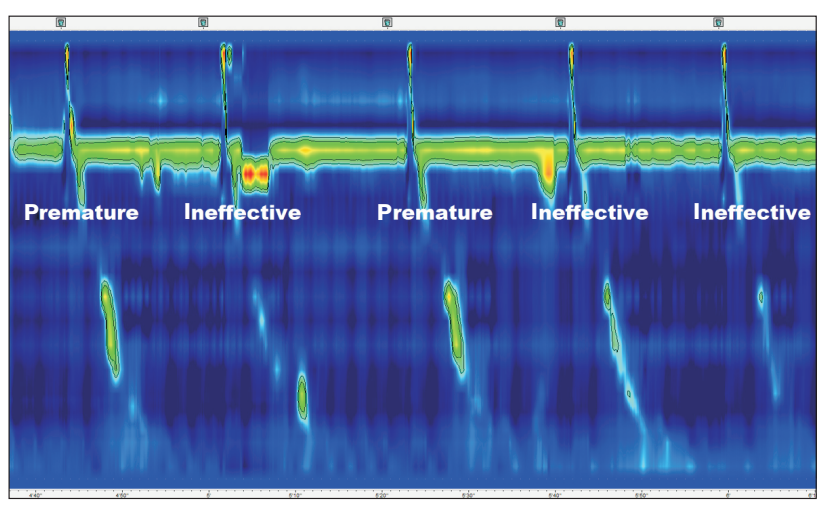

Figure 5. Individual with $50 \%$ of ineffective swallows and $20 \%$ of premature waves is diagnosed as distal esophageal spasm and not ineffective esophageal motility due to a hierarchization of diagnosis.

\section{Conclusions}

Although the Chicago classification in his 3.0 version simplified previous classification, there are still several cases that may be very difficult to interpret. A careful analysis following the definitions and hierarchization proposed is often sufficient to reach a correct diagnosis. In some difficult cases, such as for the differentiation among achalasia type I, absent peristalsis and severe ineffective esophageal motility, parameters may be similar but high-resolution manometry also allows a visual interpretation of the motility. The distinction between type II EGJ morphology and simply LES excursion is based solely on visual judgment.

\section{Financial support: None.}

\section{Conflicts of interest: None.}

Author contributions: Fernando A M Herbella: acquisition of data, analysis and interpretation of data, drafting the article, and final approval of the version to be published; Francisco Schlottmann: drafting the article and final approval of the version to be published;

\section{The Chicago classification v3.0}

Hierarchical analysis

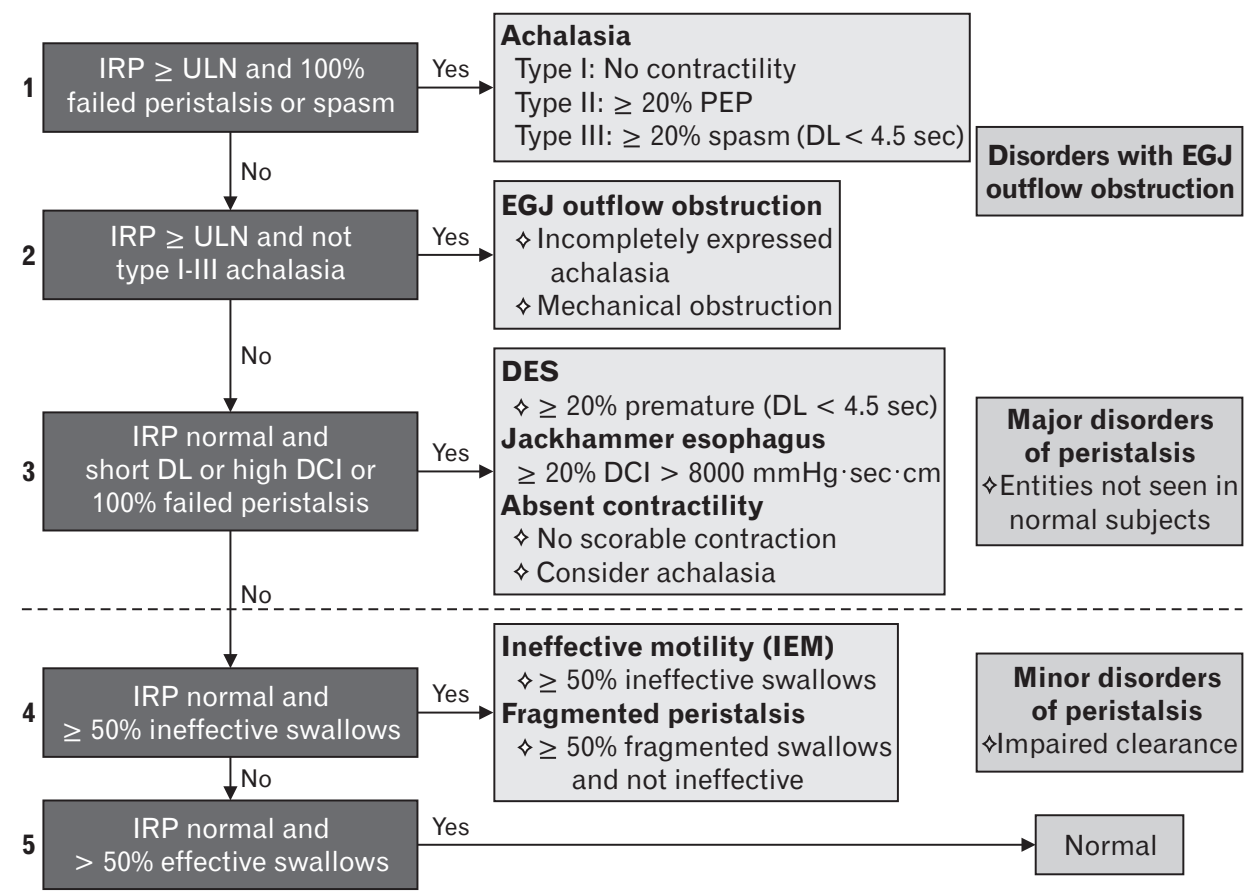

Figure 6. Hierarchization of diagnosis according to the Chicago classification version 3.0. Reproduced with permission from Kahrilas et al. ${ }^{1}$ IRP, integrated relaxation pressure; ULN, upper limit of normal; PEP, panesophageal pressurization; DL, distal latency; EGJ, esophagogastric junction morphology; DCI, distal contractile integral; IEM, ineffective esophageal motility. 
and Marco G Patti: review for intellectual content, drafting the article, and final approval of the version to be published.

\section{References}

1. Kahrilas PJ, Bredenoord AJ, Fox M, Roman A, Smout AJPM, Pandolfino JE; International High Resolution Manometry Working Group. The Chicago classification of esophageal motility disorders, v3.0. Neurogastroenterol Motil 2015;27:160-174.

2. Lafraia FM, Herbella FAM, Kalluf JR, Patti MG. A pictorial presentation of esophageal high resolution manometry current parameters. Arq Bras Cir Dig 2017;30:69-71.

3. Herbella FA, Armijo PR, Patti MG. A pictorial presentation of 3.0 Chicago classification for esophageal motility disorders. Einstein (Sao Paulo) 2016;14:439-442.

4. Schlottmann F, Herbella FA, Patti MG. Understanding the Chicago classification: from tracings to patients. J Neurogastroenterol Motil 2017;23:487-494.

5. Pandolfino JE, Kim H, Ghosh SK, Clarke JO, Zhang Q, Kahrilas PJ. High-resolution manometry of the EGJ: an analysis of crural diaphragm function in GERD. Am J Gastroenterol 2007;102:1056-1063.
6. Herbella FA, Vicentine FP, Del Grande JC. High-resolution and conventional manometry in the assessment of the lower esophageal sphincter length. J Gastrointest Surg 2010;14:1466-1467.

7. Aanen MC, Bredenoord AJ, Samsom M, Smout AJ. The gastrooesophageal common cavity revisited. Neurogastroenterol Motil 2006;18:1056-1061.

8. Roman S, Holloway R, Keller J, et al. Validation of criteria for the definition of transient lower esophageal sphincter relaxations using highresolution manometry. Neurogastroenterol Motil 2017;29:e12920.

9. Laurino-Neto RM, Herbella F, Schlottmann F, Patti M. Evaluation of esophageal achalasia: from symptoms to the Chicago classification. Arq Bras Cir Dig 2018;31:e1376.

10. Patti MG, Herbella FA. Achalasia and other esophageal motility disorders. J Gastrointest Surg 2011;15:703-707.

11. Vicentine FP, Herbella FA, Allaix ME, Silva LC, Patti MG. Comparison of idiopathic achalasia and Chagas' disease esophagopathy at the light of high-resolution manometry. Dis Esophagus 2014;27:128-133.

12. Quader F, Mauro A, Savarino E, et al. Jackhammer esophagus with and without esophagogastric junction outflow obstruction demonstrates altered neural control resembling type 3 achalasia. Neurogastroenterol Motil 2019;31:e13678. 